\title{
Educators' Perceptions on Refugee Students' Identity Challenges Following Higher Education Through Virtual Learning
}

\author{
Cassandra Sturgeon Delia ${ }^{1}$ \\ ${ }^{1}$ Curriculum Department, MCAST, Poala, Malta \\ Correspondence: Cassandra Sturgeon Delia, Curriculum Department, MCAST, Poala, Malta. E-mail: \\ cassandra.sturgeon@mcast.edu.mt
}

Received: November 1, 2021

Accepted: November 30, 2021

Online Published: December 30, 2021

doi:10.5430/irhe.v6n4p1

URL: https://doi.org/10.5430/irhe.v6n4p1

\begin{abstract}
Refugees experience specific challenges when transitioning into higher education influenced by socio-cultural issues (Kong et al., 2016). Moreover, online learning may impact identity formation leading to duelling identities (Brunton et al., 2019). As virtual learning prevails in higher education due to the globalisation of new technologies, academic needs and competition with international institutions (Olaniran \& Agnello, 2008), marginalisation of socially excluded groups such as refugees may surface (Crea \& Sparnon, 2017).

The purpose of this study is to explore educators perspectives of challenges and opportunities refugee students' face when following higher education via a virtual space that impedes these specific students identity and sense of belonging. This paper provides the concept based on Erickson's psychosocial development theory to extend this area of investigation by assessing the impact of learning via online spaces on identity.

Five educators working within higher education were interviewed using a qualitative phenomenological methodology to generate an in-depth, unique perspective on the challenges and opportunities observed by teaching refugee students' and focusing on identity formation. The data generated were transcribed verbatim and analysed using a computer-assisted data analysis software (CAQDAS), NVivo 12 Plus, to classify group-specific codebooks emerging from the data collection.

The finding suggests that refugee students' studying via a virtual space face specific challenges linked to their lived reality; however, pedagogy and educators need to be more culturally responsive to support students from diverse backgrounds and aid in the identity transition. Moreover, opportunities gained through online learning allow a sense of belonging to a global education and skills fostered will prove fruitful academically and beyond. This study concludes with implications for professional practice within the higher academic setting.
\end{abstract}

Keywords: higher education, virtual learning, refugees, identity, sense of belonging

\section{Introduction}

Global education has rapidly developed owing to technology and the implications for increasing economy and finance (Arnett, 2002), allowing higher education (HE) institutions to compete in the global market (Doiz, Lasagabaster \& Sierra, 2013). By implementing technology and offering courses virtually, HE institutes can compete with national and international establishments providing opportunities for many to study at a distance. Although online learning offers many well-documented opportunities (Adedoyin \& Soykan, (2020); Delia, 2022), communication technology used to enhance virtual learning can be complex within the age of globalisation, challenging culture and one's identity (Koc, 2006). Globalisation driven by technology has been scrutinised by scholars alike, theorising the perception of loss of time and space resulting in disembedded and declining association with localities (Giddens, 1991; Tomlinson, 1999), causing identity to become diminished, taking on a sense of shifted identity (Clifford, 1992; Koc, 2006). Thus the one size fits all scenario promised by neoliberals (Olaniran \& Agnello, 2008) cannot apply to some minority groups, such as refugees.

According to the United Nations High Commissioner for Refugees (UNHCR), there are almost 26 million refugees worldwide (Refugees, 2020). Refugees can access free education and training to support integration successfully (Ager \& Strang, 2008); moreover, as most refugees are primarily young, accepting refugees into mainstream education helps protect them and enhance their lives. Students' with a refugee status face many educational 
challenges, including lack of perception of new learning and teaching environments, technology and language difficulty and insufficient staff apprehension to the refugees learning needs (Morrice, 2014; Kong et al., 2016; Halkic \& Arnold, 2019).

In addition to those, refugees face the challenge of adapting to the local culture while remaining linked to their native culture; hence introducing online learning may cause the development of a bicultural identity, much related to globalisation (Arnett, 2002). Adolescents from occidental cultures are more globally conscious due to globalisation (Giddens, 1991); moreover, refugees immigrating from non-Western cultures could suffer identity confusion, reducing their probability of adapting to changes around them (Arnett, 2002). Such events can exclude refugees from their native and the new hosting culture, making them a part of neither (Brunton et al., 2019).

This study took place within one HE organisation in Malta that, prior to the COVID-19 pandemic, only offered traditional means of teaching, thus class-based; however, in response to government demands, had to shift teaching to online overnight in March 2020.

Identity can be defined as a state of integrity that develops over time (Brunton et al., 2019) and holds a critical learning position (Öztok, 2016). The notion of identity is an important aspect to address in HE, particularly with refugee students who struggle with their identity due to their refugee experience (Margos \& Margaroni, 2018).

This study explores educators' perceptions of the challenges and opportunities refugee students' face following online learning in HE, attempting to establish the connection between virtual learning, identity development and a sense of belonging ( $\mathrm{SoB}$ ). Moreover, this study provides detailed information on educators pedagogy challenges that may help understand critical variables affecting the students' identity. The theoretical framework applied to analyse the data will be based on Erickson's psychosocial development theory to explore online learning and how identity is affected.

To gain an in-depth understanding of the experience, the following research questions were addressed:

RQs 1: What challenges does online learning impede on identity in refugee students?

RQs 2: What are the opportunities observed when refugees follow online learning?

As the pandemic persists, implicating online teaching may persevere in traditional HE institutions. Therefore, researching educators' perceptions on refugee students' identity challenges when learning on virtual spaces deserves more attention to understand how refugee students may be supported when studying by virtual means. The study focuses on educators to provide detailed information on refugee students' experiences, considering the content and pedagogy that the students themselves may not necessarily connect. The pedagogical aspect of virtual learning can provide an important area of inquiry that is currently lacking. Understanding how technology can bring considerable alterations in culture by distorting the way people see the world (Koc, 2006) makes it essential to understand the globalisation of technology in HE and its relationship with culture. When dealing with underprivileged students' coming from underdeveloped countries that have yet to settle within the host county and familiarise themselves with the culture; introducing such students' to a larger world through technology and online learning could further add to failing of association to localities (Koc. 2006), moreover leading to an identity crisis (Arnett, 2002).

\section{Literature Review}

\subsection{Globalisation and Global Education}

The phenomenon of globalisation has reformed the socio-economic status of the world. However, challenges globalisation has brought forth, including social, political, environmental and cultural, may be overlooked by many nations (Olaniran \& Agnello, 2008). Globalisation has intensified as technology connects third world countries to central economic districts (Arnett, 2002), causing cultural impacts such as changes in values and attitudes, leading to a global consumerism society (Wilson III, 1998). Moreover, globalisation has also created a trend for global education, presenting new challenges for HE, including the teaching structure to foster international research and education (Trubek, 2001). One may argue that the globalisation of HE may imply neoliberal disputes; however, Buckner (2017) discusses how HE is anticipated to push for global standardisation and global competitiveness, the discourse reveals an emerging contribution towards global human growth.

\subsection{Learning via Virtual Spaces in Higher Education}

The implications of technology in HE are to reduce geographical constraints whilst enhancing and facilitating innovative social identities while offering a cultural, political and social advantage. However, within such dimensions, educators need to be aware of the challenges technology can impede within such realms (Koc, 2006). Online learning has been praised for its convenience, a cheaper option in terms of mobility, and flexibility owing to 
asynchronous learning, not forgetting how traditional pedagogy turned to this solution during the ongoing COVID-19 pandemic (Dhawan, 2020). However, students' unacquainted with an online learning environment may further struggle as this pedagogy requires time management, self-control and motivation, whilst having a sound support system (Arnold et al., 2018). Evidence also points to a cultural barrier when employing online learning on account of instructional design of online courses and inequalities of access and competencies to use technology (Crea \& Sparnon, 2017); thus, the cultural background must be taken into account (Zhao et al., 2020). Language barriers and the learning pedagogy are also cultural issues that may prove restrictive for certain cultures (Halkic \& Arnold, 2019). Moreover, when you add unsettled living situations such as those experienced by refugees, many considerations must be taken.

\subsection{Refugee and Higher Education}

The UNHCR (2020) define a refugee as any man, woman or child that flees their country out of fear, seeking safety and refuge outside their country of origin. Refugees lack educational prospects (Margos \& Margaroni, 2018); consequently, it is estimated that only $1 \%$ of such population make their way into HE due to challenges including language barriers, missing educational documents, legal status and unstable living conditions (Halkic \& Arnold, 2019). UNESCO (2017) argue that depriving refugee youth of HE could lead to unfulfillment of their potential, risking frustration and lack of incentive, especially when many refugees are determined to study and aspire to gain lifelong skills and abilities (Morrice, 2007). During the transition to their host country, refugee's struggle with their sense of identity, as long processing periods impact their psychological welfare (Brunton et al., 2019). Koc (2006) describes identity as the self-familiarity with oneself correlated closely with belonging. Moreover, identity is a life-long process attributed to the past; however, ever-transforming due to socio-cultural advances (Hall, 1996). Experiencing a life-altering change may cause a struggle in identity (Brunton et al., 2019), especially when refugees endure mental and physical strain whilst seeking asylum (Farrell et al., 2020). Moreover, partaking in HE has been found to empower and develop refugees mindset by equipping them with essential critical skills (Crea \& McFarland, 2015). However, difficulty adjusting to unfamiliar customs and traditions (Townsend, 2008), along with social exclusion, may impede refugees from having high educational aspirations (UNHCR, 2015).

\subsection{Identity, Belonging and Virtual Learning}

Virtual learning also presents challenges concerning identity. As the virtual world is now overtaking the physical space where individuals once met, the concept of a shrinking world by Harvey (1989) portrays how social relationships, by the globalisation of technology, has affected the identity of individuals and communities (Koc, 2006). Refugees balance a bicultural identity rooted in their country of origin while forming a new local identity. However, globalisation of technology also form's a global identity, which for refugees adapting to unfamiliar values and cultures may result in identity confusion as the worldwide culture may appear too unobtainable (Arnett, 2002). A SoB is a crucial element in the educational context for students to feel accepted, safe and supported (Peacock \& Cowan, 2019) that aids in the formation of identity, even through virtual means (Scholtes, Hout and Koppen, 2016). Gaining a SoB may be the positive emotional connection needed to form a new identity (Blanchard \& Markus, 2002), especially in refugees struggling through the process of acculturation (Margos \& Margaroni, 2018).

According to Erikson's (1968) theory of identity, adolescents seek their identity by exploring their values and beliefs to find a sense of self-worth. However, refugees expelled from their local culture and marginalised within a new culture that may not share their traditions may give rise to a sense of alienation (Arnett, 2002). Previous studies in virtual learning have also described virtual spaces as a cause of alienation if a SoB is not fostered (Exter, Korkmaz, Harlin, \& Bichelmeyer, 2009). Dealing with discrimination, segregation, unwantedness, and racism (Kong et al., 2016) may stir feelings of estrangement towards a country or an institution, influencing their identity formation and SoB (Brunton et al., 2019; Kuhu \& Nelson, 2018). When studying online, refugees carrying bicultural identities may be at greater risk of identity confusion as identity becomes more fluid when adopting new technologies (Olaniran \& Agnello, 2008) without having a chance to build a local identity nurtured within a traditional educational system. Moreover, the refugee's culture may also influence the willingness to adopt online learning (Zhao et a., 2020).

A number of studies have addressed the challenges faced by refugees learning through virtual spaces (Crea \& Sparnon, 2017; Farrell et al., 2020; Halkic \& Arnold, 2019; ), while other studies investigated how using technology to learn may affect identity (Brodie \& Osowka, 2021; Brunton et al., 2019; Koc, 2006; Öztok, 2016). Existing research has focused on the transitioning refugee identity in HE; however, an educators perspective that can critique the pedagogy and link how the educative content affects the refugees' identity is lacking. Previous research has primarily overlooked educators' perspectives on online learning and refugees' identity, which could establish a connection between virtual spaces and the importance of pedagogical content to preserve identity. 


\section{Methodology}

For this study, a phenomenological approach was utilised to understand the fundamental essence experienced by educators teaching refugees online. Phenomenology was chosen as a research method to explore and identify the challenges and opportunities online learning offers in HE as it allows the focus from the educators lived experience. The epistemological basis of the methodological approach was attempted as it can produce a deep and more precise picture of this professional group (Forster, 2016) by interpreting gathered narratives to yield the experience explored and identify relationships between such encounters. The specific HE organisation was chosen due to the high intake of refugees annually as part of a governmental and NGO collaboration. Collecting educators experiences is essential to address how the challenges and opportunities of online teaching affect the refugee students' identity development and how this relates to their SoB. Furthermore, shared strategies to online teaching allow an inclusive approach towards different cultures. The focus on the challenges when teaching refugee students' online in HE specifically, rather than international students', proves essential as this minority group already proves difficult because of their lack of resources and structure in their everyday lives within a refugee open camp or shared apartments.

\subsection{Data Generation}

The sample for this study included five educators within the higher education sector that had taught refugee students' online for longer than three months. The recruitment was based on a purposive sampling including educators within the same organisation that fit the inclusion criteria (Table 1). Five educators, three female and two males that ranged between the ages of 28 to 42 years old, were approached by email, describing the aim of the study and how data would be collected. The educators online classes were mixed, including local, international and students holding the refugee status. As this study addresses educators perceptions, the researcher opted for in-depth interviews with open-ended questions to gain a more profound stance into the participant's observations. After obtaining consent to participate and to be recorded, interviews were conducted through an online platform that facilitated transcription of the meeting's audio recording. Interviews took place over a timeframe of two weeks- each of them lasting about 50 mins.

The admissions and records office confirmed the student's refugee status to ensure correct inclusion. Refugee students referred to in this study originated from Eritrea, Somalia and Sudan.

Table 1. Inclusion \& exclusion criteria

\begin{tabular}{cc}
\hline \multicolumn{1}{c}{ Inclusion } & Exclusion \\
\hline Educators teaching in higher education & Other educators \\
\hline $\begin{array}{c}\text { Educators delivering modules fully online } \\
\begin{array}{c}\text { Educators teaching mixed cohorts including } \\
\text { those holding a refugee status }\end{array}\end{array}$ & $\begin{array}{c}\text { Educators delivering modules partially online or } \\
\text { face to face }\end{array}$ \\
\hline
\end{tabular}

Ongoing module longer than three months Short module less than three months

Qualified male and male educators

\subsection{Analysis}

The transcribed verbatim generated from the interviews were inputted in a computer-assisted data analysis software (CAQDAS), NVivo 12 Plus, a qualitative software created by QSR International (Melbourne, Australia) to classify group-specific codebooks emerging from the data generated. Data were further analysed in a data-driven manner rather than a structured method; hence findings emerged in iterative patterns guided by the comparisons found in the discourse resulting in logical and coherent practicable portions, where categories emerged by distributing similarities into manageable headings according to grouped concepts (Corbin \& Strauss, 2014). The themes presented in the 
discussion show definitive experiences to emphasise the challenges and opportunities discussed in rich data sets by using Erickson's psychosocial development theory to emerge the transformation of identity and how this relates to a SoB. Moreover, representative quotes were included by referring to the generated data to emerge the educators' perceptions on identity formation in the refugee students.

\subsection{Ethical Issues and Validity}

Ethical approval was sought prior to commencing the study. As this study involved human subjects, approval was granted after careful consideration that all ethical practices were in place to protect the integrity of all those involved. The author stated that all data collected should retain anonymity, and confidentiality shall be respected. Only the author had access to the recordings and password-protected data that were discarded after the study period.

Two initial interviews were performed to ensure that the questions demonstrated the intent of use, using the intended questions to seek any adjustments needed of the tool beforehand. The first pilot in-depth interview ran for 45 minutes using semi-structured open-ended questions. After the interview, the questionnaire and answers were analysed to observe the strengths and weaknesses of the tool. Improvements were addressed according to the answers gained. Questions that did not reflect the research questions were carefully amended. The researcher also had to self-reflect on the interview to amend questions that did not effectively give the intended result. The interviewee, being also an educator and familiar with the development of surveys, was asked for feedback on the sequence and logic of the questions to gain a better insight into the effectiveness of such questions. These amended questions were tested in the second pilot interview, which ran for about the same time frame.

\section{Discussion of Findings}

This study explored educators' perceptions of refugee students' challenges and opportunities when studying via a virtual space concerning identity formation. The findings indicate that while refugees face specific challenges based on their situation, they cope with these barriers by adapting to a new emerging identity and a found SoB within the online environment. Through the data-led analysis, three themes emerged: 1) challenges and impact on identity, 2) emerging opportunities, and 3) impact on a sense of belonging.

\subsection{Challenges and Impact on Identity}

The challenges refugee students' face is linked to the cultural transition and the acculturative stress associated with resettlement to a new host country and a new learning style.

Participants reported challenges that included language barrier, lack of IT skills, being new to online learning and limited access to the internet, that although correlate well with others finding (Koc, 2006; Kong et al., 2016; Crea \& Sparson, 2017; Halkic \& Arnold, 2019), these are not challenges specific to this ethnic minority group alone. Negative feelings with regards to lack of living space, lack of privacy to learn online within shared refugee camps, and dealing with background noise and cramped environments, however, was found to be a specific challenge:

"Students had issues with support from shared living space. It would be understood that this is an online lecture; however, at least one out of the five students had trouble controlling their immediate area and even during important presentations for assessments, I could hear and see children running and others shouting behind the students". (Participant 1)

Living conditions were discussed unanimously, indicating how students' would be unwilling to turn on the camera due to their dire living conditions that relate well with findings by O'Reilly (2018). Such a limited private physical environment was identified as a challenge. Hence the classroom could aid to assimilate a local identity as a student and as part of the community; however, being away from other students and the campus dampened the adaptive process. Learning in isolation, disconnected from others, made their situation "all too real" and made their identity transition slower:

"Not having the basic needs to carry out online learning swiftly reminds them of their situation. When learning from home, they are too wrapped up in their reality". (participant 2)

The classroom was referred to as a supportive environment for refugees; it was an escape from the harsh living conditions. This finding is consistent with Farrell et al. (2020), who found that the asylum world and the study world clashed, creating a stressful experience to balance both worlds, especially learning within an environment that generates anxiety, loneliness, stress and depression.

Moreover, the pedagogy was unsatisfactory to teach students with different cultural backgrounds. Participants emphasised this specific pedagogical challenge as being a brick-and-mortar education without adapting to different cultural needs: 
"A student studying stone masonry, concerning heritage building, could not carry out an assignment effectively as they did not have the basic knowledge on Mediterranean region stone. He was familiar with the resources within his region, however not limestone significant in Maltese masonry". (Participant 3)

The pedagogy adopted should support students' from diverse backgrounds to progress academically by building students' strengths (Gay, 2018) and creating a pedagogy relevant for students with diverse backgrounds (Wearmouth, 2017b). Taking into account students' prior knowledge of the taught activities, where subjects and literary may be foreign to them, is a significant challenge that could lead to angst and distress (Wearmouth, 2017 ${ }^{\mathrm{a}}$ ).

In addition to inadequate pedagogy and lack of socio-cultural staff awareness, these learners face being a new student in a foreign culture that plays a challenging role regarding the perception of their identity (Kahu \& Nelson, 2018). Furthermore, the online learning mode disembodies such students' from affiliating to the host locality (Giddens, 1991), further forming an identity to the new host country. Socio-cultural issues specific to refugees questions their sense of identity, to the point, that they may be dwelling between identities previously held and the identity of an online learner (Brunton et al., 2019). New experiences as an online learner and within a new culture could emerge a whole new identity as Bhabha (1996) described, revealing the concept of an emerging hybrid identity fusing the new with the past.

\subsection{Emerging Opportunities}

Online learning created opportunities both for the students and the educators alike. Students' formed online relationships and bonded with other students, especially among refugees, helping each other to find solutions to the resource and IT challenges:

"Forming of friendship were mostly with other refugees. They felt a need to bond with others who are either refugees like them or others with similar problems. When asking if they needed help, they would state that they were meeting up with another student (refugee) that offered to help them". (Participant 4)

This finding is congruent with the work of Farrell et al. (2020), who supports the notion that refugee students' form peers as a support system that positively affects their learning experience. As part of the complex process in identity development, building relationships with different peers has been linked to reduced anxiety and doubt while promoting positive attitudes, achieving openness to diversity (Gerson \& Neilson, 2014); hence opportunities for intercultural sensitivity were observed for non-refugee students', which could be fruitful academically and beyond (Streitwieser et al., 2018). Throughout the modules, students' became more comfortable with online learning and trust was built:

"Some women felt comfortable online and participated without the hijab, allowing others to them in a different light". (Participant 2)

Online learning gave refugees a new set of skills that they can foster and utilise to set a professional path making them more independent for future roles. Furthermore, online learning allowed them to gain a broader perspective on life and make up their own identity rather than being confined to a refugee identity. As identity is a transformational process (Hall, 1990), online learning may be discussed as a space to develop and shed the refugee label and transform into a new representation that aids their new position in a globalised world (Vigil \& Abidi, 2018). The discourse revealed how local, international and refugee students' alike had the opportunity to practice the English language in a mixed online platform.

Educators had the opportunity to reflect on their current pedagogy regarding how culturally adapted they perceived the pedagogy. The results yielded that educators felt that it was not equipt to teach such diverse, multicultural students' and expressed a desire to improve the pedagogy to ensure bridging cultural barriers. The findings suggest that educators felt they were not equipped with enough knowledge on the students' background and previous literacy practices:

"The best way forward to teach refugees as part of a mixed class would be to have a community of practice with other educators, where we share ideas of best practices, because sometimes what you do might not work with a certain cohort, but it might work with another. We could swap pedagogies to get a better outcome. I would feel more at ease having support". (Participant 5)

Educators lack awareness of the student's situation and the challenges they face, which affects the students' progress and educators teaching practice (Earnest et al., 2010). Addressing cultural pedagogical challenges reduces inequalities in teaching and allows culturally responsive curriculum development that is imperative to avoid ostracism of one's identity (Wearmouth, 2017 ). Educators need to recognise and respond to diverse cultures. 
However, ensuring cultural responsiveness should start with a top-down approach to ensure the students' connection to the curriculum for effective education (Gardner, 2014) and build a learning identity (Bruner, 1996).

\subsection{Impact on a Sense of Belonging}

A feeling that one does not belong impedes engagement, student success and identity formation (Kahu \& Nelson, 2018). Moreover, holding a refugee label creates tensions with self-identity creating an "us" and "them" perception (Vigil \& Abidi, 2018); thus, the more challenges the refugee students' face, the longer it takes to create a new identity and gain a SoB.

The finding suggests that educators found the refugee students' lacking familiarity with technology and had expressed feeling "out of place" learning via a virtual space. Older students showed more self-confidence to over-power difficult situations; however, younger refugees were less self-aware of their abilities. A representative comment includes:

"Online learning could go two ways for refugee students. They could cut themselves off completely as they find the situation too foreign or build themselves up and become an active part of the online community. Most try very hard. You can see how they struggle. However, they face it head-on". (Participant 5)

These findings suggest that the students were still able to adapt to online learning and acquire an identity as an online learner, regardless of the barriers, and through participation and regular attendance, they achieved a SoB within a virtual space, giving them a routine and hope for the future. The present data are consistent with previous literature (Crea \& McFarland, 2015; Brunton et al., 2019; Farrell et al., 2020).

The mixed group dynamics also affected the students'SoB, as students' would be willing to mentor and help others with academic difficulties, technical problems, share notes and create groups on social media for group work. The educational institution offered help with resources, including offering laptops and headsets that encouraged a sense of being part of the HE institute.

\section{Conclusion}

Both local and international students face challenges with online learning in HE; however, refugees are more likely to face challenges of a specific nature due to traumatic events (Margos \& Margaroni, 2018) leading up to and resettlement in a new host country (Earnest, Housen \& Gillieatt, 2007).

This research paper aimed to discuss educators' perceptions of refugees' challenges and opportunities concerning identity development when learning virtually in HE. The findings revealed how identity formation was impeded by the reality of a refugee living in poor conditions and other refugee non-specific challenges that hindered their SoB. Nevertheless, the educators identified refugees students' achieving a fruitful transition and managing a SoB to an online community through peer support and willingness. Moreover, educators felt that they lacked the know-how to teach culturally diverse groups and the pedagogy lacked a student-centred approach that culturally responsive pedagogy should hold.

The finding of this paper supports the current literature by implying challenges and opportunities specific to refugees. However, it also offers an insight into identity transformation as observed from educators perspective and an emphasis for recognising the need of re-aligning curriculum and educators training to better suit refugee needs in online HE.

Limitations of this study are recognised here as being a small scale qualitative study that cannot be generalised to other populations or institutions. Moreover, the staff participating here are new to online teaching; hence this study may not capture the dynamic range of online learning. As participants were chosen purposefully, this study cannot generalise to the population. Future implications for this study recommend that management and policy-makers recognise specific challenges refugees face, including cultural and pedagogy barriers, to ensure student retention and not face identity marginalisation.

\section{Acknowledgements}

This research was undertaken as part of the $\mathrm{PhD}$ in e-Research and Technology Enhanced Learning in the Department of Educational Research at Lancaster University. The author is pleased to acknowledge the contribution of the lead lecturer Dr Murat Öztok and peers in supporting the development of this study and its report as an assignment paper.

Funding: No funding was sought for this study. 


\section{References}

Adedoyin, O. B., \& Soykan, E. (2020). Covid-19 pandemic and online learning: the challenges and opportunities. Interactive Learning Environments, 1-13. https://doi.org/10.1080/10494820.2020.1813180

Ager, A., \& Strang, A. (2008). Understanding integration: A conceptual framework. Journal of refugee studies, 21(2), 166-191. https://doi.org/10.1093/jrs/fen016

Arnett, J. J. (2002). The psychology of globalisation. The American Psychologist, 57(10), 774-783. https://doi.org/10.1037/0003-066X.57.10.774

Arnold, P., Kilian, L., Thillosen, A., \& Zimmer, G. M. (2018). Handbuch E-Learning: Lehren und Lernen mit digitalen Medien (Vol. 4965). UTB. https://doi.org/10.36198/9783838549651

Bhabha, H. K. (1996). Culture's in-between. Questions of Cultural Identity, 1, 53-60. https://doi.org/10.4135/9781446221907.n4

Blanchard, A. L., \& Markus, M. L. (2002, January). Sense of virtual community-maintaining the experience of belonging. In Proceedings of the 35th Annual Hawaii International Conference on System Sciences (pp. 3566-3575). IEEE.

Brodie, J., \& Osowka, R. (2021). Supporting entrepreneurship students' sense of belonging in online virtual spaces. Industry and Higher Education, 35(4), 353-359. https://doi.org/10.1177\%2F0950422221999264

Bruner, J. (1996). The culture of education. Harvard University Press.

Brunton, J., Farrell, O., Costello, E., Delaney, L., Foley, C., \& Brown, M. (2019). Duelling Identities in Refugees Learning through Open, Online Higher Education. Open Praxis, 11(4), 397-408. https://doi.org/10.5944/openpraxis.11.4.1018

Buckner, E. S. (2017). The changing discourse on higher education and the nation-state, 1960-2010. Higher Education, 74(3), 473-489. https://doi.org/10.1007/s10734-016-0056-2

Clifford, J. (1992). Travelling Cultures in Grossberg L, Nelson C \& Treichler P. Cultural Studies.

Corbin, J., \& Strauss, A. (2014). Basics of qualitative research: Techniques and procedures for developing grounded theory. Sage publications.

Crea, T. M., \& McFarland, M. (2015). Higher education for refugees: Lessons from a 4-year pilot project. International Review of Education, 61(2), 235-245. https://doi.org/10.1007/s11159-015-9484-y

Crea, T. M., \& Sparnon, N. (2017). Democratising education at the margins: Faculty and practitioner perspectives on delivering online tertiary education for refugees. International Journal of Educational Technology in Higher Education, 14(1), 1-19. https://doi.org/10.1186/s41239-017-0081-y

Delia, C. S. (2022). The effect of mLearning on motivation in the Continuing Professional Development of nursing professionals: A Self-Determination Theory perspective. Journal of Nursing Education and Practice, 12(3). https://doi.org/10.5430/jnep.v12n3p22

Dhawan, S. (2020). Online learning: A panacea in the time of COVID-19 crisis. Journal of Educational Technology Systems, 49(1), 5-22. https://doi.org/10.1177/0047239520934018

Doiz, A., Lasagabaster, D., \& Sierra, J. (2013). Globalisation, internationalisation, multilingualism and linguistic strains in higher education. Studies in higher education, 38(9), 1407-1421. https://doi.org/10.1080/03075079.2011.642349

Earnest, J., Housen, T., \& Gillieatt, S. (2007). Adolescent and young refugee perspectives on psychosocial well-being. Perth: Centre for International Health: Curtin University of Technology.

Earnest, J., Joyce, A., De Mori, G., \& Silvagni, G. (2010). Are universities responding to the needs of students' from refugee backgrounds? Australian Journal of Education, 54(2), 155-174. https://doi.org/10.1177/000494411005400204

Erikson, E. H. (1968). Identity: Youth and crisis (No. 7). WW Norton \& company.

Exter, M. E., Korkmaz, N., Harlin, N. M., \& Bichelmeyer, B. A. (2009). SENSE OF COMMUNITY WITHIN A FULLY ONLINE PROGRAM Perspectives of Graduate Students. Quarterly Review of Distance Education, $10(2)$. 
Farrell, O., Brunton, J., Costello, E., Delaney, L., Brown, M., \& Foley, C. (2020). 'This is two different worlds, you have the asylum world and you have the study world': an exploration of refugee participation in online Irish higher education. Research in Learning Technology, 20, 1-15. https://doi.org/10.25304/rlt.v28.2368

Forster, M. (2016). Phenomenography: A methodology for information literacy research. Journal of Librarianship and Information Science, 48(4), 353-362. https://doi.org/10.1177/0961000614566481

Gay, G. (2018). Culturally responsive teaching: Theory, research, and practice. Teachers College Press.

Gerson, M. W., \& Neilson, L. (2014). The importance of identity development, principled moral reasoning, and empathy as predictors of openness to diversity in emerging adults. Sage Open, 4(4), 2158244014553584. https://doi.org/10.1177/2158244014553584

Giddens, A. (1991). 1991Modernity and Self-Identity. Self and Society in the Late Modern.

Halkic, B., \& Arnold, P. (2019). Refugees and online education: student perspectives on need and support in the context of (online) higher education. Learning, Media and Technology, 44(3), 345-364.

Hall, S. (1990). Cultural identity and diaspora.

Hall, S. (1996). Who needs identity. Questions of Cultural Identity, 16(2), 1-17.

Kahu, E. R., \& Nelson, K. (2018). Student engagement in the educational interface: understanding the mechanisms of student success. Higher Education Research \& Development, 37(1), 58-71. https://doi.org/10.1080/07294360.2017.1344197

Koc, M. (2006). Cultural identity crisis in the age of globalisation and technology. Turkish Online Journal of Educational Technology-TOJET, 5(1), 37-43.

Kong, E., Harmsworth, S., Rajaeian, M. M., Parkes, G., Bishop, S., AlMansouri, B., \& Lawrence, J. (2016). University transition challenges for first year domestic CALD students from refugee backgrounds: A case study from an Australian regional university. Australian Journal of Adult Learning, 56(2), 170-197.

Magos, K., \& Margaroni, M. (2018). The importance of educating refugees. Global Education Review, 5(4), 1-6.

Morrice, L. (2014). The learning migration nexus: towards a conceptual understanding. European Journal for Research on the Education and Learning of Adults, 5(2), 149-159. https://doi.org/10.3384/rela.2000-7426.rela9044

O'Reilly, Z. (2018). 'Living Liminality': everyday experiences of asylum seekers in the 'Direct Provision'system in Ireland. Gender, Place \& Culture, 25(6), 821-842. https://doi.org/10.1080/0966369X.2018.1473345

Olaniran, B. A., \& Agnello, M. F. (2008). Globalisation, educational hegemony, and higher education. Multicultural Education \& Technology Journal. https://doi.org/10.1108/17504970810883351

Öztok, M. (2016). Cultural ways of constructing knowledge: The role of identities in online group discussions. International Journal of Computer-Supported Collaborative Learning, 11(2), 157-186. https://doi.org/10.1007/s11412-016-9233-7

Peacock, S., \& Cowan, J. (2019). Promoting Sense of Belonging in Online Learning Community of Inquiry in Accredited Courses. Online Learning Journal, 67-81. https://doi.org/10.24059/olj.v23i2.1488

Refugees, U. (2020). Figures at a Glance. Retrieved 14 November 2020, from https://www.unhcr.org/figures-at-a-glance.html

Scholtes, V., Hout, M. V., \& Koppen, L. V. (2016). Can People Develop a Sense of Belonging Through Playing League of Legends? ACE '16: Proceedings of the 13th International Conference on Advances in Computer Entertainment Technology (pp. 1-6). Osaka: ACM Digital Library. https://doi.org/10.1145/3001773.3001784

Streitwieser, B., Loo, B., Ohorodnik, M., \& Jeong, J. (2019). Access for refugees into higher education: A review of interventions in North America and Europe. Journal of Studies in International Education, 23(4), 473-496. https://doi.org/10.1177/1028315318813201

Tomlinson, J. (1999). Globalisation and culture. University of Chicago Press.

Townsend, R. (2008). Adult Education, Social Inclusion and Cultural Diversity in Regional Communities. Australian Journal of Adult Learning, 48(1), 71-92.

Trubek, D. M. (2001). The future of international studies. Changing Perspectives on International Education, 298-319. 
UN High Commissioner for Refugees (UNHCR), Sustainable Development Goal 4 and Refugee Education, July 2015. Retrieved 7 December 2020, from https://www.refworld.org/docid/59c368ed4.html

UNHCR (2020). What is a refugee? Retrieved 12 November 2020, from https://www.unhcr.org/what-is-a-refugee.html

Vigil, Y. N., \& Baillie Abidi, C. (2018). "We" the refugees: Reflections on refugee labels and identities. Refuge: Canada's Journal on Refugees/Refuge: revue canadienne sur les réfugiés, 34(2), 52-60. https://doi.org/10.7202/1055576ar

Wearmouth, J. (2017a). Special educational needs and disabilities in schools: a critical introduction. Bloomsbury Publishing.

Wearmouth, J. (2017b). Employing culturally responsive pedagogy to foster literacy learning in schools. Cogent Education, 4(1), 1295824. https://doi.org/10.1080/2331186X.2017.1295824

Wilson III, E. J. (1998). Globalisation, information technology, and conflict in the second and third worlds. A Critical Review of Literature, Project on World Security. Rockefeller Brothers Foundation, New York, NY.

Zhao, Y., Wang, N., Li, Y., Zhou, R., \& Li, S. (2021). Do cultural differences affect users'e-learning adoption? A meta-analysis. British Journal of Educational Technology, 52(1), 20-41. https://doi.org/10.1111/bjet.13002

\section{Copyrights}

Copyright for this article is retained by the author(s), with first publication rights granted to the journal.

This is an open-access article distributed under the terms and conditions of the Creative Commons Attribution license (http://creativecommons.org/licenses/by/4.0/). 